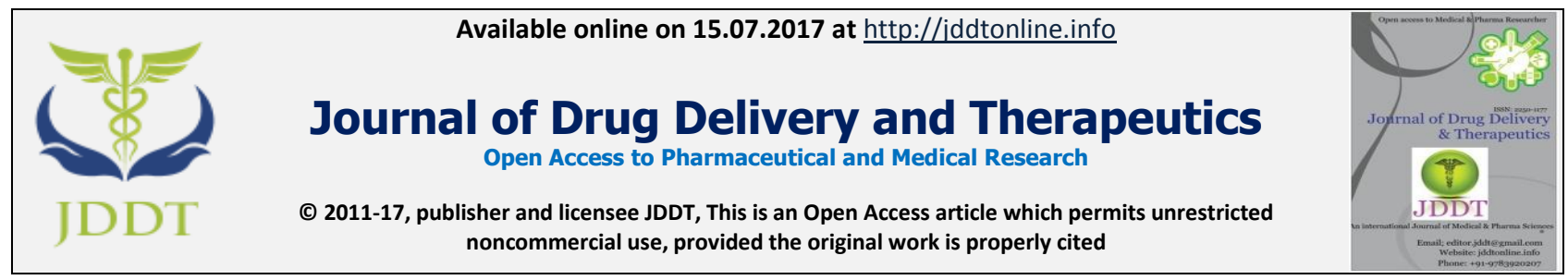

Open Access

Research Article

\title{
KNOWLEDGE, ATTITUDES AND PRACTICES REGARDING ANTIBIOTIC USE AMONG THE STUDENTS OF MICROBIOLOGY DEPARTMENT AT NOAKHALI SCIENCE AND TECHNOLOGY UNIVERSITY, BANGLADESH
}

\author{
Sanjoy Kumar Mukharjee*, Iqbal Mahmud, Shajida Akter, Shakaout Hossain \\ Department of Microbiology, Noakhali Science and Technology University, Noakhali-3814, Bangladesh
}

\begin{abstract}
Antibiotic resistance is a worldwide public health concern now and only proper knowledge and practices can solve the problem. This study was aimed to evaluate the knowledge, attitudes, and practices regarding antibiotic use among the University students who study Microbiology. In January- February 2017, a cross-sectional study was conducted amongst 266 students of the Microbiology department at the Noakhali Science and Technology University in Bangladesh. Students of all the academic years (first year to masters) took part in this study. A self-administered questionnaire was provided during regular lectures. The questionnaire included demographic characteristics of participants and 25 questions about their knowledge, attitudes and actual practices about antibiotic use. Collected data was analyzed using Microsoft Excel and Statistical package for social sciences (SPSS). In a case of knowledge, $23.7 \%$ of the respondents stated that antibiotics are appropriate for viral infections, $48.9 \%$ think that antibiotics can speed up the recovery of cold and cough and $45.9 \%$ provided a positive response regarding the better efficacy of newer and costly antibiotics. Overall attitude towards antibiotic resistance is good among total students (87.6\%-100\%). Student's practices regarding proper antibiotic use $(63.5 \%-84.6 \%)$ is poor than their knowledge and attitudes. About half $(52.26 \%)$ of the students took antibiotic last year and of them, $75.5 \%$ took those antibiotics through the professional doctor's prescription. A high proportion of the study participants $(36.5 \%)$ mentioned that they usually take antibiotic for fever and $31.6 \%$ said they started an antibiotic therapy after a simple doctor call or without a proper medical examination. Students of the Microbiology department in Noakhali Science and Technology University have a fair knowledge and attitude about antibiotic usage but their practices of antibiotic usage need to be improved. As these Students are the future contributor of the health sector in Bangladesh, their proper knowledge and practices are highly expected.
\end{abstract}

Keywords: Antibiotic, Resistance, Microbiology, Students, Knowledge, Attitudes, Practices.

Article Info: Received 02 May, 2017; Review Completed 18 June, 2017; Accepted 19 June, 2017; Available online 15 July, 2017

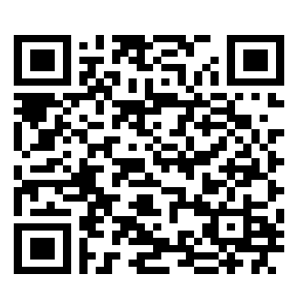

Cite this article as:

Mukharjee SK, Mahmud I, Akter S, Hossain S, Knowledge, attitudes and practices regarding antibiotic use among the students of microbiology department at Noakhali Science and Technology University, Bangladesh, Journal of Drug Delivery and Therapeutics. 2017; 7(4):34-37

DOI: http://dx.doi.org/10.22270/jddt.v7i4.1456

*Address for Correspondence

Sanjoy Kumar Mukharjee, Department of Microbiology, Noakhali Science and Technology University, Noakhali-3814, Bangladesh E-mail: sanjoy.dumb@gmail.com

\section{INTRODUCTION}

Antibiotics are one of the most commonly prescribed, sold and used drugs worldwide. But irrational and overuse of antibiotics result in the emergence of antibiotic resistant bacteria which has become a global public health concern in recent decades 1,2,3. Despite public awareness and concern of health care providers, global irrational use of antibiotics is ascending. In many countries antibiotics are sold even without prescription of doctors and are used in an inappropriate way but this tends to carry more significance in the developing world ${ }^{4}$.

Students who study Microbiology are exposed to knowledge about disease and drugs. Being a future 
researcher of health care providing system their skills and knowledge in this regard are critical ${ }^{5}$. Previous researches revealed different patterns of inappropriate knowledge, attitude and behavior about antibiotics among University students $6,7,8,9$. But until now there is only limited data available about the condition in Bangladeshi University students who study Microbiology as major. Therefore, the aim of this study was to investigate the level of knowledge, attitude and behavior of the students of Microbiology department in Noakhali Science and Technology University, Bangladesh.

\section{MATERIALS AND METHODS}

A cross-sectional study was carried out among the 266 students of Microbiology department at the Noakhali Science and Technology University during the period January- February, 2017. The participation of students in this study was voluntary, and the students were informed that the completion and submission of the questionnaire would be taken as their consent to participate in this study. A high level of confidentiality and anonymity was maintained throughout the study.

The self administered questionnaire had a total number of 25 questions, covering three major themes (knowledge, attitudes and practices). The questionnaire was developed after a literature review of comparable studies and previously validated by a pilot study on 10 students of the same department ${ }^{10-14}$. The first part included their personal knowledge regarding antibiotics and antibiotic usage. The second part comprised the attitude of the participants regarding antibiotic resistance and antibiotic awareness programs. The third part contained information about antibiotics usage behavior and history of the participants. The data was statistically analyzed using Statistical package for social sciences (SPSS) for Windows.

\section{RESULTS AND DISCUSSION}

A total of 266 students were participated in this survey. Respondents' demographic characteristics are summarized in Table 1 . The majority of respondents $(58.3 \%)$ were male. The mean age of the participants was $22 \pm 1.8$ years old. Over half of the respondents $(52.3 \%)$ used antibiotic at least once last year. Students of different levels of study (first year to masters) participated in this survey at the rate of $9.8-32.7 \%$. More than half of the participant's $(58.7 \%)$ relatives work in the health related field that demands the better understanding of the participants regarding safe use of antibiotics.

Table 1: General characteristics of respondents ( $N=266)$.

\begin{tabular}{|c|c|c|c|}
\hline \multicolumn{2}{|c|}{ Demographic variables } & Frequency & Percentage (\%) \\
\hline \multirow{2}{*}{ Gender } & Male & 155 & 58.3 \\
\cline { 2 - 4 } & Female & 111 & 41.7 \\
\hline Age & & \multicolumn{3}{|c|}{$22( \pm 1.8)^{\mathrm{a}}$} \\
\hline \multirow{3}{*}{ Year of study } & First & 55 & 20.7 \\
\cline { 2 - 4 } & Second & 58 & 21.8 \\
\cline { 2 - 4 } & Third & 87 & 32.7 \\
\cline { 2 - 4 } & Fourth & 40 & 15 \\
\cline { 2 - 4 } & Masters & 26 & 9.8 \\
\hline \multirow{2}{*}{ Antibiotic use in last year } & Yes & 139 & 52.3 \\
\cline { 2 - 4 } & No & 127 & 47.7 \\
\hline \multirow{2}{*}{ Relatives working in health related field } & Yes & 110 & 41.4 \\
\cline { 2 - 4 } & No & 156 & 58.7 \\
\hline
\end{tabular}

The participants demonstrated a good knowledge about antibiotics. Percentages of fully correct answers were higher than $76 \%$ in two third of the questions proposed. Regarding the knowledge about antibiotic use, almost all the participants were aware that antibiotics are useful for treating bacterial infections $(92.1 \%)$ and overwhelming majority heard about antibiotic resistance (97\%). $86.1 \%$ participants think that frequent use of antibiotics will decrease efficacy of treatment when using the antibiotic again. A relatively low percentage of the sample $(76.3 \%)$ was conscious that antibiotics are not appropriate for viral infections. The lowest percentage was reached for the question "Do you think the use of antibiotics will speed up the recovery of cold, cough?" and only $51.1 \%$ of the students responded correctly. Another lowest percentage question was "Is the efficacy better if the antibiotics are newer and more costly?" and only 54\% respondents provided correct answer (Table 2).

Concerning attitudes on antibiotic use and overall condition in Bangladesh, all the students (100\%) stated that it is necessary to get more education about antibiotics. 96.2\% think that there is abuse on antibiotics and $94.4 \%$ think this abuse is the main reason for bacterial antibiotic resistance. $92.1 \%$ participants believe that antibiotic resistance has become a problem in Bangladesh now. Relatively low percentage (87.6\%) thinks that antibiotic resistance can affect the respondents and their family's health. However, highest percentage $(97.7 \%)$ thinks that there is a necessity of establishing course on 'rational use of antibiotics' at University and $97 \%$ thinks the necessity to carry out large-scale 'antibiotics campaign' promotion (Table 3). 
Table 2: Respondents' knowledge regarding antibiotics $(\mathrm{N}=266)$.

Statements evaluating respondents' knowledge towards antibiotics (Correct response)

Frequency Percentage

Can antibiotics cure bacterial infections? (YES)

Can antibiotic cure viral infections? (NO)

Do you think the use of antibiotics will speed up the recovery of cold, cough? (NO)

Have you heard of antibiotics resistance? (YES)

Do you think frequent use of antibiotics will decrease efficacy of treatment when using the antibiotic again? (YES)

Is the efficacy better if the antibiotics are newer and more costly? (NO)

\begin{tabular}{|c|c|}
\hline 245 & 92.1 \\
\hline 203 & 76.3 \\
\hline 136 & 51.1 \\
\hline 258 & 97 \\
\hline 229 & 86.1 \\
\hline 144 & 54 \\
\hline
\end{tabular}

Table 3: Respondents' attitudes regarding antibiotics ( $\mathbf{N}=266)$.

\section{Statements evaluating respondents' attitude towards antibiotics (Correct response)}

Frequency $\quad$ Percentage

There is abuse on antibiotics at present (YES)

Antibiotics resistance has become a problem in Bangladesh. (YES)

Abuse of antibiotics has become the main cause leading to bacterial resistance (YES)

Antibiotic resistance affects you and your family's health (YES)

Necessary to get more education about antibiotics (YES)

Need to establish course on 'rational use of antibiotics' at University (YES)

Necessary to carry out large-scale ‘antibiotics campaign' promotion (YES)

In case of actual practice, $79 \%$ usually do not take antibiotics for flu or cold or a sore throat and $63.5 \%$ do not take antibiotic for fever. In case of doctors association, $84.6 \%$ take antibiotic only when prescribed by the doctor, $72.6 \%$ do not buy antibiotics without a medical receipt and $68.4 \%$ never started an antibiotic therapy after a simple doctor call, without a proper medical examination. These are good practices but rest of the respondents have bad practices of buying antibiotics without doctor's prescription of proper medical examination which is alarming. Moreover, $32.7 \%$ respondents keep leftovers antibiotics at home because they might be useful in the future and $29.9 \%$ respondents stop taking antibiotic when you start feeling better. These practices indicate the alarming situation regarding inappropriate use of antibiotic and subsequent development of antibiotic resistant bacteria ${ }^{13}$ (Table 4).

Table 4: Respondents' practices regarding antibiotics usage $(\mathrm{N}=266)$.

\begin{tabular}{|l|c|c|}
\hline $\begin{array}{l}\text { Statements evaluating respondents' practices towards antibiotics (Response of proper } \\
\text { practice) }\end{array}$ & Frequency & Percentage \\
\hline Do you usually take antibiotic for cold or sore throat? (NO) & 210 & 79 \\
\hline Do you usually take antibiotic for fever? (NO) & 169 & 63.5 \\
\hline Do you usually stop taking antibiotic when you start feeling better? (NO) & 189 & 71.1 \\
\hline Do you take antibiotic only when prescribed by the doctor? (YES) & 225 & 84.6 \\
\hline Do you keep leftovers antibiotics at home because they might be useful in the future? (NO) & 179 & 67.3 \\
\hline $\begin{array}{l}\text { Do you use leftovers antibiotics when you have cold, sore throat or flu without consulting } \\
\text { your doctor? (NO) }\end{array}$ & 208 & 78.2 \\
\hline Do you buy antibiotics without a medical receipt? (NO) & 193 & 72.6 \\
\hline $\begin{array}{l}\text { Have you ever started an antibiotic therapy after a simple doctor call, without a proper } \\
\text { medical examination? (NO) }\end{array}$ & 182 & 68.4 \\
\hline
\end{tabular}

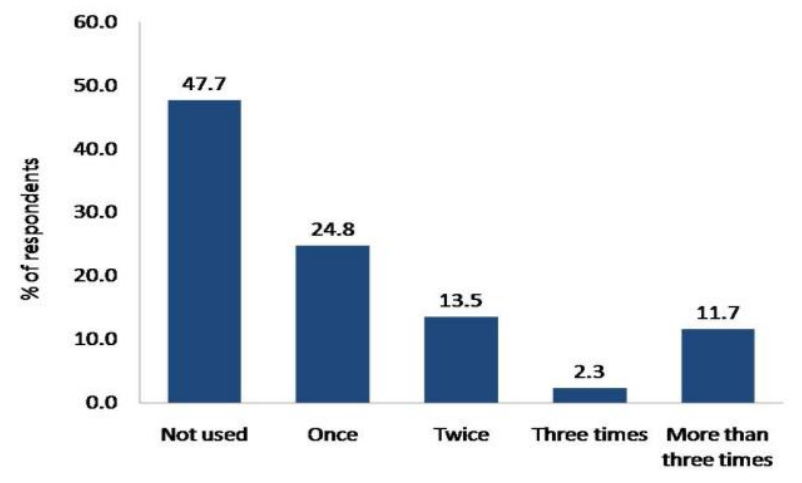

Figure 1: The frequency of antibiotic use by respondents in last year.

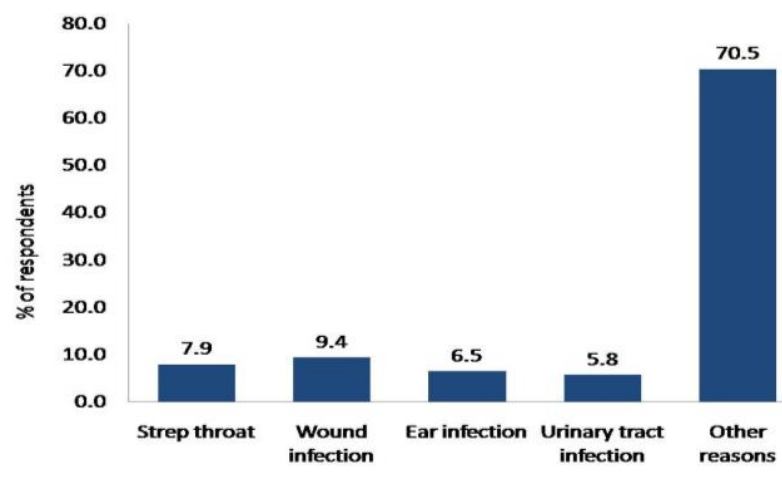

Figure 2: Respondents reasons of taking antibiotic in last year. 


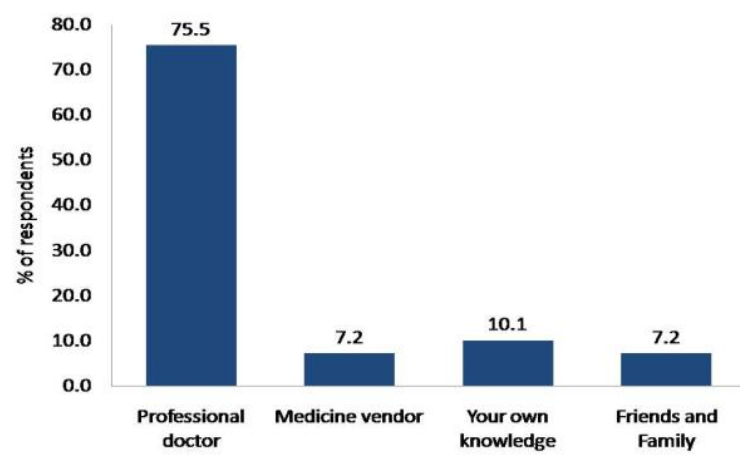

Figure 3: The sources of antibiotics obtained by the respondents.

Among the respondents who $(52.3 \%)$ used antibiotic at least once last year, highest percentage (24.8\%) took antibiotic only once and $11.7 \%$ took more than three times (Figure 1). $70.5 \%$ used antibiotics due to the reasons other than strep throat, wound infection, ear infection and urinary tract infection (Figure 2). $75.5 \%$ took antibiotic after consulting with professional doctor (Figure 3).

Our findings showed that, despite the good level of knowledge about antibiotics, high rates of inappropriate behaviors were observed. Hence, it seems like despite having sufficient theoretical backgrounds, Students of Microbiology department in Noakhali Science and Technology University does not practice what they learn. These results are confirmed by recent studies on this topic which showed how almost all the participated students interviewed were aware about inappropriate use of antimicrobials but reluctant in case of proper practice ${ }^{15}$.

This study presents several strengths and limitations. Firstly, it is the first study investigating this issue amongst University students of Microbiology department in Bangladesh. Secondly, the study samples cover all the students from entry level (first year) to higher level (Masters) and no students refused to complete the questionnaire, resulting in a high rate of responses. However, the limitations of the study are mainly related to the study design. For instance, a self-administered questionnaire was used in this study instead of the face toface interviews that are traditionally considered the gold standard method of survey administration ${ }^{16,17}$. Therefore, Similar to all other self administered surveys, the accuracy of the results of this study was heavily dependent on the honesty and understanding of the respondents. Furthermore, a larger-scale study is needed where more students of Microbiology department from different Universities would share their understanding and behavior about antibiotic use and misuse which could possibly help to develop a concrete decision about their actual knowledge and awareness.

\section{CONCLUSIONS}

The present study revealed a good knowledge of Microbiology students regarding the antibiotics. However, despite of the theoretical results, they still have an incorrect practice concerning the antibiotics consumption. The Microbiology students are the future contributor of health sector and at the same time they represent a behavioral model for educated citizens and patients. Therefore, efforts should be focused to raise the awareness among these students during the degree courses to improve knowledge and change attitudes and practices towards antibiotic use.

\section{CONFLICT OF INTEREST}

The authors claim no conflict of interest for this research work.

\section{REFERENCES}

1. Bronzwaer SLAM, Cars O, Buchholz U, Mölstad S, Goettsch W, Veldhuijzen IK, Kool JL, Sprenger MJW, Degener JE and participants in the European Antimicrobial Resistance Surveillance System, The relationship between antimicrobial use and antimicrobial resistance in Europe, Emerg Infect Dis, 2002; 8(3):278-282.

2. Goossens H, Ferech M, Stichele RV, Elseviers $M$ for the ESAC Project Group, Outpatient antibiotic use in Europe and association with resistance: a cross-national database study, Lancet, 2005: 365(9459):579-587.

3. Gyssens IC, Quality measures of antimicrobial drug use, Int $\mathbf{J}$ Antimicrob Agents, 2001; 17:9-19.

4. Donkor ES, Tetteh-Quarcoo PB, Nartey P, Agyeman IO, Selfmedication practices with antibiotics among tertiary level students in Accra, Ghana: a cross-sectional study, Int J Environ Res Public Health, 2012; 9(10):3519-29.

5. Banerjee I, Bhadury $\mathrm{T}$, Self-medication practice among undergraduate medical students in a tertiary care medical college, West Bengal J Postgrad Med, 2012; 58(2):127-31.

6. Buke C, Hosgor-Limoncu M, Ermertcan S, Ciceklioglu M, Tuncel M, Ko“se T, Eren S, Irrational use of antibiotics among university students, J Infect, 2005; 51:135-139.

7. Lv B, Zhou Z, Xu G, Yang D, Wu L, Shen Q, Jiang M, Wang $\mathrm{X}$, Zhao G, Yang S, Fang Y, Knowledge, attitudes and practices concerning self-medication with antibiotics among university students in western China, Trop Med Int Health, 2014; 19(7):769-779.

8. Suaifan G ARY, Shehadeh M, Darwish DA, Al-ljel H, Yousef AM, Darwish RM, A cross-sectional study on knowledge, attitude, and behavior related to antibiotic use and resistance, among medical and nonmedical university students in Jordan, Afr J Pharm Pharacol, 2012; 6(10):763-770.

9. El Ezz NF, Ez-Elarab HS, Knowledge, attitude and practice of medical students towards self medication at Ain Shams University, Egypt, J Prev Med Hyg, 2011; 52(4):196-200.

10. Scaioli G, Gualano MR, Gili R, Masucci S, Bert F, Siliquini R, Antibiotic Use: A CrossSectional Survey Assessing the Knowledge, Attitudes and Practices amongst Students of a School of Medicine in Italy, PLoS ONE, 2015; 10(4):e0122476. doi:10.1371/journal.pone.0122476.

11. Huang Y, Gu J, Zhang M, Ren Z, Yang W, Chen Y, et al. Knowledge, attitude and practice of antibiotics: a questionnaire study among 2500 Chinese students, BMC Med Educ, 2013; 13:163.

12. Dyar OJ, Howard P, Nathwani D, Pulcini C, Knowledge, attitudes, and beliefs of French medical students about antibiotic prescribing and resistance, Médecine Mal Infect, 2013; 43(10):423-430.

13. Khan AKA, Banu GKKR. Antibiotic Resistance and Usage-A Survey on the Knowledge, Attitude, Perceptions and Practices among the Medical Students of a Southern Indian Teaching Hospital, J Clin Diagn Res, 2013; 7(8):1613-1616.

14. André M, Vernby A, Berg J, Stalsby LC, A survey of public knowledge and awareness related to antibiotic use and resistance in Sweden, J Antimicrob Chemother, 2010; 65(6):1292-1296.

15. Abbo LM, Cosgrove SE, Pottinger PS, Pereyra M, SinkowitzCochran R, Srinivasan A, Medical students' perceptions and knowledge about antimicrobial stewardship: how are we educating our future prescribers?, Clin Infect Dis. 2013; 57(5):631-638.

16. De Leeuw E, Hox J, Dillmann D, International Handbook of Survey Methodology, New York: Taylor \& Francis Group, 2008.

17. Groves RM, Fowler FJ, Couper MP, Lepkowski JM, Eleanor SE, Tourangeau R, Survey Methodology, New Jersey: John Wiley \& Sons, 2004 